\title{
Estimation of soil aggregate stability indices using artificial neural network and multiple linear regression models
}

\section{AUTHORS}

\section{Marashi M. ${ }^{1}$}

\section{Mohammadi}

Torkashvand A. ${ }^{\circledR, 1}$

m.torkashvand54@

yahoo.com

\section{Ahmadi A. ${ }^{2}$ \\ Esfandyari M. ${ }^{1}$}

@ Corresponding Author

${ }^{1}$ Department of Soil

Science, Science and

Research Branch, Islamic

Azad University. Tehran,

Iran.

2 Department of Soil

Science, University of

Tabriz. Tabriz, Iran.
Estimación de indices de estabilidad de agregados de suelo mediante redes neuronales artificiales y modelos de regresión múltiple linear

Estimativa de indices de estabilidade de agregados do solo usando redes neuronais artificiais e modelos de regressão linear múltipla

\section{Received: 29.12.2016 | Revised: 05.05.2017 | Accepted: 11.05.2017}

\section{ABSTRACT}

During recent decades, an artificial intelligence system has been used for developing the pedotransfer functions (PTFs) for estimation of soil properties. In the present study, the capabilities of multiple linear regression (MLR) and artificial neural networks (ANNs) in developing PTFs for estimating mean weight diameter (MWD) from routine soil properties (P1) and combination of routine soil properties and fractal dimension of aggregates (P2) were evaluated. The results showed that the ANN model for estimating MWD is more accurate than the MLR model. Application of fractal dimension of aggregates as a predictor in both methods improved the accuracy of PTFs.

\section{RESUMEN}

Durante las últimas décadas se ha utilizado un sistema de inteligencia artificial para desarrollar funciones de pedotransferencia (PTFs) que permiten estimar las propiedades del suelo. En este trabajo se evaluó la capacidad del modelo de regresión múltiple linear (MLR) y de las redes neuronales artificiales (ANNs) para desarrollar PTFs que permitan estimar el diámetro medio ponderado (MWD) a partir de propiedades rutinarias del suelo (P1) y de la combinación de propiedades rutinarias del suelo y agregados de dimension fractal (P2). Los resultados mostraron que el modelo ANN para estimar el MWD es más exacto que el modelo MLR. La aplicación de la dimensión fractal de los agregados como herramienta de predicción en ambos métodos mejoró la exactitud de las PTFs.

\section{RESUMO}

Durante as últimas décadas, tem sido usado um sistema de inteligência artificial para desenvolver funçôes de pedotransferência (PTFs) que permitam estimar as propriedades do solo. Neste estudo, foram avaliadas as capacidades do modelo de regressão linear múltipla (MLR) e das redes neuronais artificiais (ANNs) para o desenvolvimento de $P T F$ s que permitam estimar o diâmetro ponderado médio (MWD) a partir das propriedades clássicas do solo (P1) e da combinação destas propriedades do solo e da dimensão fractal dos agregados (P2). Os resultados mostraram que o modelo ANN para estimar o MWD é mais exato que o modelo MLR. A aplicação da dimensão fractal dos agregados em ambos os métodos melhorou a precisão dos PTFs. 


\section{Introduction}

Evaluation and measurement of soil erosion in fields is often expensive or time-consuming. Thus, soil aggregate stability (SAS) indexes could be used as the main indicators in erodibility and resistivity to mechanical stresses of soil. A lowering of the SAS index enhances soil degradation and soil erodibility. The concept of SAS is usually determined by the destructive action of water on soil aggregates. Several indexes including geometric mean diameter (GMD) and mean weight diameter (MWD) of aggregates are directly used to characterize and quantify the SAS. Nevertheless, measurement and quantitative description of these indexes are difficult and time-consuming (Alijanpour Shalmani et al. 2011). Thus, prediction of these indexes could be done indirectly via easily available data (which are closely correlated with SAS index) such as clay, organic matter, and pH (Cañasveras et al. 2010). Due to their electrical charge, clay particles and polysaccharides in the components of organic matters bind inorganic soil particles into stable aggregates, therefore they could increase SAS. The concept of fractal dimension (Dn) is the other relatively method for describing soil structure in a quantitative style (Parent et al. 2011). Based on their particle numbers and sizes, those fractals appeared to be appropriate to model the soil aggregation building process. Several studies showed that fractal geometry could be a useful tool in quantifying scale-dependent soil characteristics such as aggregate mass, particle mass, and soil particle surface (Zhao et al. 2006; de Boer et al. 2000). So, fractal geometry could also be used as another easily available property to predict and estimate SAS.

The use of simulation modeling has increased rapidly in recent decades. Pedotransfer functions (PTFs) are undirected methods that predict time-consuming soil properties from easily and readily measured properties. Nowadays, using artificial neural networks (ANNs) has been increased for developing PTFs (Bocco et al. 2010; Gago et al. 2010; Besalatpour et al. 2013). ANNs are generally the computing systems which mimic biological neural networks (Saffari et al. 2009) and finally can learn patterns and predict. The input layer, hidden layer(s), and an output layer of neurons are the main parts of each ANN structure (Tracey et al. 2011). Besalatpour et al. (2013) predicted the wet soil aggregate stability from easily available properties by ANFIS, ANN, generalized linear model (GLM), and multiple linear regressions (MLR). Their results showed that ANN and ANFIS models showed greater potential in predicting SAS from soil and site characteristics, whereas linear regression methods did not perform well. Several studies reported that in nonlinear data like soil properties, ANN models are reliable and simple useful prediction tools in soil analysis (Kisi et al. 2009; Huang et al. 2010; Silva et al. 2010; Besalatpour et al. 2013). Hence, the objectives of this study were to evaluate and compare the capabilities of ANN and multiple linear regression (MLR) to develop PTFs between SAS indices (MWD) and various sets of input variables. 


\section{Materials and methods}

2.1. Study area, soil sampling, and laboratory analysis

East Azerbaijan province with an area of 45491 square kilometers is located in the north-west of Iran, between $39^{\circ} 26^{\prime}-36^{\circ} 45^{\prime} \mathrm{N}$ latitudes and $45^{\circ} 5^{\prime}-48^{\circ} 22^{\prime} E$ longitudes, and has mostly foothills and mountains. The highest peak of East Azerbaijan is Sahand Mountain with $3,722 \mathrm{~m}$ height. The province includes arid and semi-arid climates. Drawing upon 43 years of data, the average annual rainfall is reported as
$300 \mathrm{~mm}$ and it varies between 254 to $452 \mathrm{~mm}$, and the average temperature varies between 7.6 to $12.7^{\circ} \mathrm{C}$, across the province.

One hundred soil samples with diverse properties were collected $(0-30 \mathrm{~cm}$ depth) from the northwest of Iran (Figure 1). Then soils samples was air-dried and passed through a $2 \mathrm{~mm}$ sieve. Then, some soil properties such as soil texture were determined by hydrometer (Gee and Or 2002), cation exchange capacity (CEC) by sodium acetate (Bower et al. 1952), and organic carbon (OC) by wet oxidation and Walkey and Black (1934) methods. A factor of 1.72 can be used to convert OC to soil organic matter (OM) content (Sparks et al. 1996).

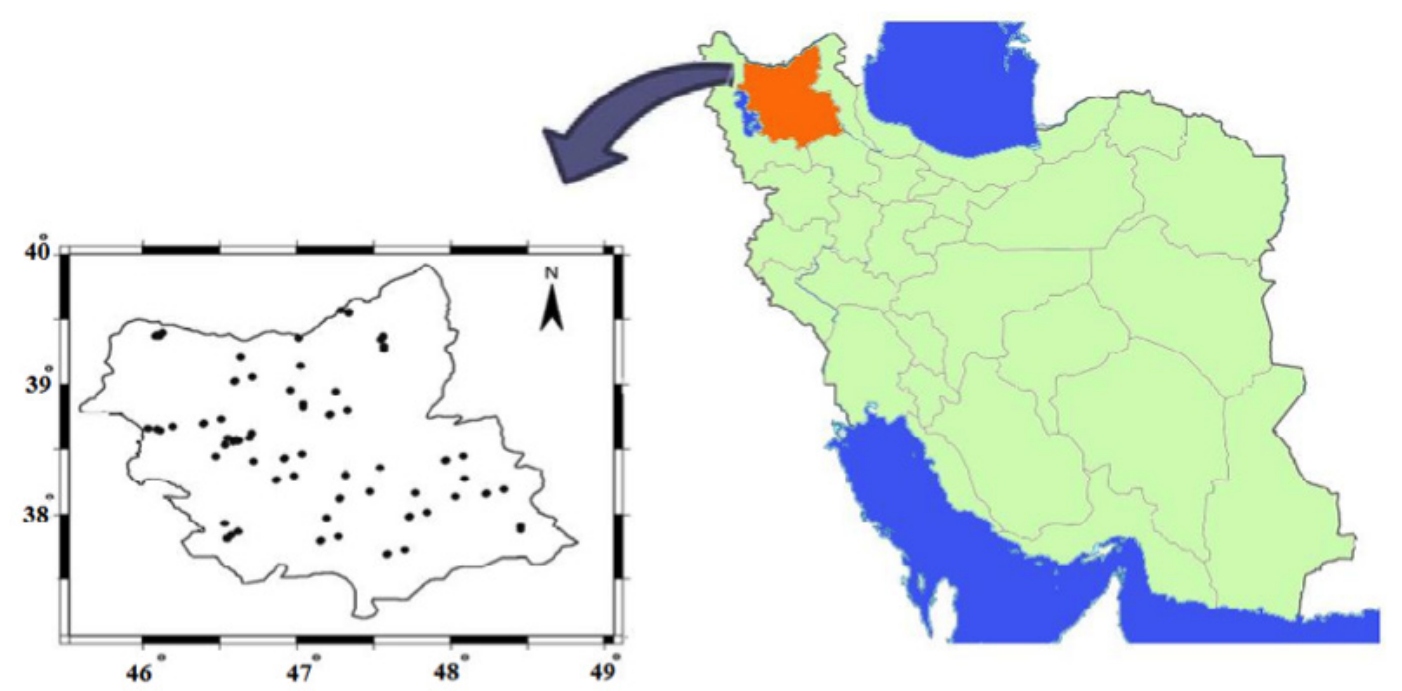

Figure 1. Geographical distribution of studied soil samples in East Azerbaijan province of Iran.

The mean weight diameter (MWD) of wet-sieved aggregates was measured by the method proposed by Nimmo and Perkins (2002). The MWD (mm) of water-stable aggregates were calculated using the following equation:

$$
M W D=\sum_{i=1}^{n} W i \bar{X} i
$$

where:

$\bar{X} i$ : mean of the remained aggregates diameter on the sieve $(\mathrm{mm})$

Wi: ratio of the remained aggregates weight on the sieve to the sample total weight

$\mathrm{n}$ : the number of sieves used for separation

Fractal dimension of aggregates could be estimated between number-diameter (Dn), mass-diameter $\left(D_{m T}\right)$, and bulk density-diameter $\left(D_{m Y}\right)$ of the aggregates (Ahmadi et al. 2011). 
Ahmadi et al. (2011) studied several fractal models (Dn, $D_{m Y}$ and $D_{m Y}$ ) to estimate the fractal dimension of soil aggregates, as indexes of soil erodibility. They reported that $\mathrm{Dn}$ and $\mathrm{D}_{\mathrm{mt}}$ could be better alternative variables for predicting soil erodibility factor empirically. Hence, we choose Dn as an easily available soil property to predict SAS. For the calculation of number-based fragmentation fractal dimension of aggregates (Dn), the size distribution of aggregates was determined by the method which is described in Ahmadi et al. (2011). Then, according to Rieu and Sposito's (1991) model, Dn was calculated using the following equation:

$$
N(>x i)=K_{n}(x i)^{-D_{n}}
$$

where:

$N(>x i)$ : the cumulative number of aggregates greater than $x i$

$\mathrm{Dn}$ : the slope of the regression line of $\mathrm{N}$ versus $x i$ in the log-log scale

$\mathrm{Kn}$ : the intercept of the regression line of $\mathrm{N}$ versus $x i$ in the log-log scale

\subsection{Datasets and descriptive statistics}

Two datasets of easily and readily measured properties were applied separately as inputs for the prediction of MWD. For the investigation of the improvement of the model performance by using fractal dimension of soil aggregates as a predictor, once a PTF (marked as P2) was developed without Dn ( $2^{\text {nd }}$ dataset) as the predictor, and once again another PTF (marked as P1) was developed using Dn ( $1^{\text {st }}$ dataset) as the predictor. To determine the degree of variability of soil characteristics, we analyzed the data statistically. Classical descriptors such as mean, median, minimum, maximum, coefficient of variation (\%CV), standard deviation (SD), skewness and kurtosis of data distribution were determined using the statistical software SPSS (IBM Com., Chicago, USA). For increasing the speed and accuracy of the models' calibration, both input and output data were normalized within the range 0-1 using the following equation:

$$
N=\left[\frac{\left(X-X_{\min }\right)}{\left(X_{\max }-X_{\min }\right)}\right]
$$

$\mathrm{N}$ : Normalized data

$X$ : Measured value for the factor $X_{\min }$ and $X_{\max }$ : Minimum and maximum values in the database

For the development of PTFs, the database is randomly divided into two subsets: calibration and validation subset. Ratios for calibration and validation were chosen $85 \%$ and $15 \%$, respectively. Calibration process of ANN- and MLR-PTFs was performed by calibration (85 data) dataset. Then, ANN- and MLR-PTF's performance was evaluated by validation dataset (15 data).

\subsection{PTFs development}

\subsubsection{Multiple linear regressions (MLR) PTFs}

MLR is one of the statistical methods which attempts to model the relationship between two or more interpretive variables (independent) and a response variable (dependent) by fitting a linear equation to the observed data. The model for MLR is:

$$
y_{i}=b_{0}+b_{1} x_{i, 1}+b_{2} x_{i, 2}+\cdots+b_{k} x_{i, k}+e_{i}
$$

where $y_{i}$ is the dependent variable, b0 is a constant called the intercept, $x_{i, k}$ is an independent variable, $b_{k}$ is the vector of regression coefficients called slope, and $e_{i}$ represents random measured errors. In the present study, the statistical software SAS (Cary, NC., USA) was applied to calculate the MLR models.

\subsubsection{Artificial neural networks (ANNs) PTFs}

Multilayer perceptrons (MLPs) with LevenbergMarquardt learning algorithm as learning role (which is highly more influential than the 
conventional gradient descent techniques) was used for ANN examination.

The structural design for MLP models was done by sigmoid function (as transfer functions in inputs and output datasets), and hidden layer(s). An MLP type of ANN consists of one input layer; one or more hidden layer(s) and one output layer with a large number of inter-connected neurons. The basic structure of a typical MLP network is shown in Figure 2. An MLP could have more than one hidden layer. However, several studies showed that a single hidden layer is satisfactory for an ANN to estimate any complex nonlinear function (Kisi 2004). In the present study, the optimum number of hidden neurons and epoch was tested through trial-and-error. Calculation of ANN analysis was done using NeuroSolutions 5.05 software.

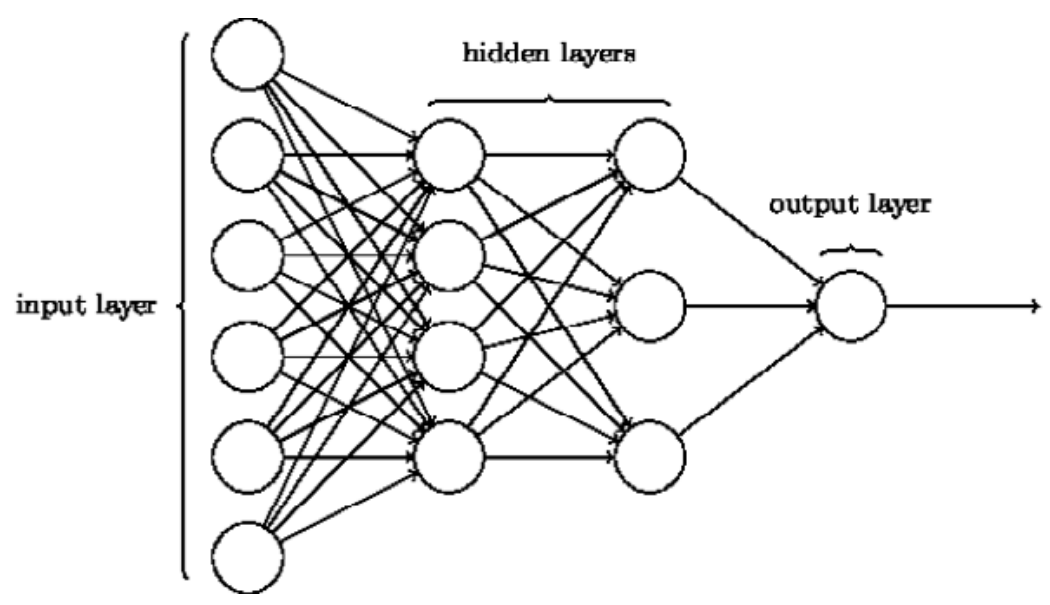

Figure 2. Schematic of a typical MLP network.

\subsection{Performance criteria}

The performance of four PTFs was assessed based on the differences between the observed and predicted MWD by the determination coefficient (R2), root mean square error (RMSE), mean absolute percentage error (MAPE), and mean absolute deviation (MAD). The four statistical parameters used to compare the performance of the three methods are defined as:

$E(x i)=$ Estimated value of observation $i$

$M(x i)=$ Measured value of observation $i$

$\mathrm{n}=$ total number of observations

$p=$ number of regression coefficients

MSE $=$ mean square error

$$
\begin{aligned}
R M S E & =\sqrt{\frac{1}{n} \sum_{i=1}^{n}[E(x i)-M(x i)]^{2}} \\
M A P E & =\frac{\frac{\sum_{i=1}^{n}[E(x i)-M(x i)]}{\sum_{i=1}^{n} M(x i)}}{n} \times 100
\end{aligned}
$$$$
M A D=\frac{\sum_{i=1}^{n}[E(x i)-M(x i)]}{n}
$$ 
$R^{2}=\left[\frac{\sum_{K=1}^{n}\left(X_{k}-\bar{X}\right)\left(Y_{k}-\bar{Y}\right)}{\sum_{K=1}^{n}\left(X_{k}-\bar{X}\right)^{2} \sum_{Y=1}^{N}(Y-\bar{Y})^{2}}\right]^{2}$

$\mathrm{Xk}=$ measured value

$\mathrm{Yk}=$ predicted value

$\mathrm{X}=$ mean of observed values

$\mathrm{Y}=$ mean of predicted values

For the assessment of performances of PTFs, the validation datasets were used.

\section{Results and discussion}

\subsection{Descriptive statistics}

Table 1 shows the statistical characteristics of the calibration and validation data for the prediction of MWD. Clay with an average of $25.8 \%(8.55 \%-$ $50.17 \%$ ) plays an important role in SAS index. Rasiah and Kay (1994) and Dimoyiannis et al. (1998) showed a significant positive correlation between clay content and SAS index. Based on data, $\mathrm{pH}$ values of the samples ranged between 6.81 and 8.3 with an average value of 7.78 , which show most of the soil samples in study area are alkaline. The amount of organic matter in soil samples varies from 0.06 to $4.38 \%$ with an average of $1.98 \%$. Idowu (2003) stated that $\mathrm{OM}$ and $\mathrm{pH}$ are the main soil properties which could improve the accuracy of the prediction of SAS. It seems that soil CEC with an average of $24.3 \mathrm{cmol}_{(+)} \mathrm{kg}^{-1}\left(6.8\right.$ to $\left.59.9 \mathrm{cmol}_{(+)} \mathrm{kg}^{-1}\right)$ could be useful in the prediction of main soil property in SAS index. However, lgwe and Mbagwu (1995) showed that CEC had no significant influence on SAS. Generally, quantities of statistical characteristics (Table 1) revealed that distributions of inputs and outputs data are normal, based on Kolmogorov-Smirnov test.

Table 1. Statistics of training and validation dataset which used for development and testing of PTFs

\begin{tabular}{|c|c|c|c|c|c|c|c|c|}
\hline Variables & Mean & Median & Max & Min & SD & Skewness & Kurtosis & $\begin{array}{l}\text { P value for } \\
\text { Kolmogorov- } \\
\text { Smirnov test }\end{array}$ \\
\hline & \multicolumn{8}{|c|}{ Training datasets $(n=85)$} \\
\hline Clay (\%) & 26.78 & 22.44 & 50.17 & 8.55 & 12.34 & 0.29 & -1.14 & 0.18 \\
\hline OM (\%) & 1.58 & 1.33 & 4.32 & 0.06 & 1.11 & 1.10 & 1.25 & 0.200 \\
\hline $\mathrm{pH}$ & 7.79 & 7.79 & 8.30 & 7.48 & 0.19 & 0.61 & 1.64 & 0.083 \\
\hline $\operatorname{CEC}\left(\mathrm{cmol}_{(+)} \mathrm{kg}^{-1}\right)$ & 22.30 & 21.30 & 49.40 & 11.00 & 8.94 & 0.99 & 2.33 & 0.150 \\
\hline Dn & 3.98 & 4.01 & 5.78 & 2.70 & 0.82 & 0.66 & 0.06 & 0.28 \\
\hline \multirow[t]{2}{*}{ MWD (mm) } & 0.23 & 0.20 & 0.55 & 0.05 & 0.11 & 1.20 & 2.53 & 0.051 \\
\hline & \multicolumn{8}{|c|}{ Validation dataset $(n=15)$} \\
\hline Clay (\%) & 24.93 & 24.78 & 38.53 & 9.75 & 8.94 & 0.02 & -0.97 & 0.061 \\
\hline OM (\%) & 2.38 & 2.33 & 4.38 & 0.12 & 1.55 & -0.03 & -1.70 & 0.071 \\
\hline $\mathrm{pH}$ & 7.78 & 7.87 & 8.19 & 6.81 & 0.39 & -1.21 & 1.26 & 0.096 \\
\hline $\mathrm{CEC}\left(\mathrm{cmol}_{(+)} \mathrm{kg}^{-1}\right)$ & 26.30 & 23.10 & 59.90 & 6.80 & 13.50 & 1.32 & 1.76 & 0.051 \\
\hline Dn & 3.77 & 3.74 & 5.26 & 2.63 & 0.66 & 0.63 & 1.19 & 0.067 \\
\hline MWD (mm) & 0.36 & 0.23 & 1.18 & 0.09 & 0.33 & 1.75 & 2.26 & 0.120 \\
\hline
\end{tabular}




\subsection{Prediction of SAS}

\subsubsection{MLR-PTFs}

Table 2 presented the evaluation criteria of the created models in the current study. Estimated data versus observed data for the validation dataset of the investigated models are also designed in Figures 3 and 4 . According to the results, among the investigated models, the MLR model had the lowest prediction accuracy. However, where the predicted and the observed values are almost gathered, the MLR model showed relatively acceptable performance in predicting MWD. Using MLR with only soil properties as the input data (P1) had lower determination coefficient $\left(R^{2}\right)$ between the observed and estimated output compared to using second dataset (P2) as input data. Prediction capability of the created MLR model using P2 was better than using P1 and a higher $\mathrm{R}^{2}$ and a lower RMSE value was obtained. The MAPE values for the created MLR model using
$\mathrm{P} 1$ were $31.52 \%$, whereas the application of P2 as input dataset decreased MAPE values $(26.20 \%)$, with respect to using P1 as input dataset, which shows that the addition of Dn had considerable effect on the accuracy of the predicted MWD by created LMR model. The MLR model is introduced as an accurate tool to evaluate soil quality (Zornoza et al. 2007), which is used by different researches to predict soil properties (Trasar-Cepeda et al. 1998; Lentzsch et al. 2005). However, in the present study, this model was to some extent poor in predicting the SAS indexes in P1 dataset. Insufficient data for developing a reasonable MLR model, as well as the sample distribution and introduced spatial variation effects could be the main reasons for the low accuracy of the MLR approach in predicting the measured SAS values (Besalatpour et al. 2012). Besalatpour et al. (2012, 2013) and Sobhani et al. (2010) reported that the regression models have low accuracy and prediction capability.

Table 2. Accuracy and reliability criteria obtained using validation dataset for MLR and ANN models which developed for prediction of MWD

\begin{tabular}{lccccccccc}
\multirow{2}{*}{ Models } & \multicolumn{9}{c}{$\mathbf{P}_{\mathbf{1}}$} \\
\cline { 2 - 10 } & $\mathrm{R}^{2}$ & RMSE & MAPE & MAD & $\mathrm{R}^{2}$ & RMSE & MAPE & MAD \\
\hline MLR & 0.78 & 0.18 & 31.52 & 0.12 & 0.90 & 0.11 & 26.20 & 0.08 \\
\hline ANN & 0.87 & 0.17 & 30.09 & 0.12 & 0.93 & 0.09 & 21.41 & 0.06 \\
\hline
\end{tabular}

P1 and P2 means that the model developed without and with using Dn as a predictor in modeling, respectively $(n=15)$.

\subsubsection{ANN-PTFs}

Several neurons and epoch were evaluated through trial-error to find the best construction of ANN for the prediction of MWD. The MLP was trained using 1 to 10 hidden layers. After each calibration, $\mathrm{R}^{2}$, MAPE, and RMSE were computed using only the validation dataset to find the suitable number of hidden layers. The results of trial-error showed that two or more hidden neurons and epoch set more than 1000, decreased the prediction efficiency of outputs, and increased RMSE. Therefore, one hidden layer and an epoch set number at 1000 were applied for the calibration of ANN model. Similar to the obtained results from MLR model, the created ANN model using P2 as an input dataset gave a greater $\mathrm{R}^{2}$ and lower RMSE in comparison with $\mathrm{P} 1$ as an input dataset. The $\mathrm{R}^{2}$, RMSE, MAPE, and MAD values in MWD prediction using ANN technique were 0.87$0.93,0.09-0.174,21.41-30.09 \%$ and $0.06-0.12$, respectively. These results suggest that the ANN model is a relatively better predictor of MWD than the MLR model. Yilmaz and Kaynar (2011) used MLR, ANN (RBF, MLP) and ANFIS 

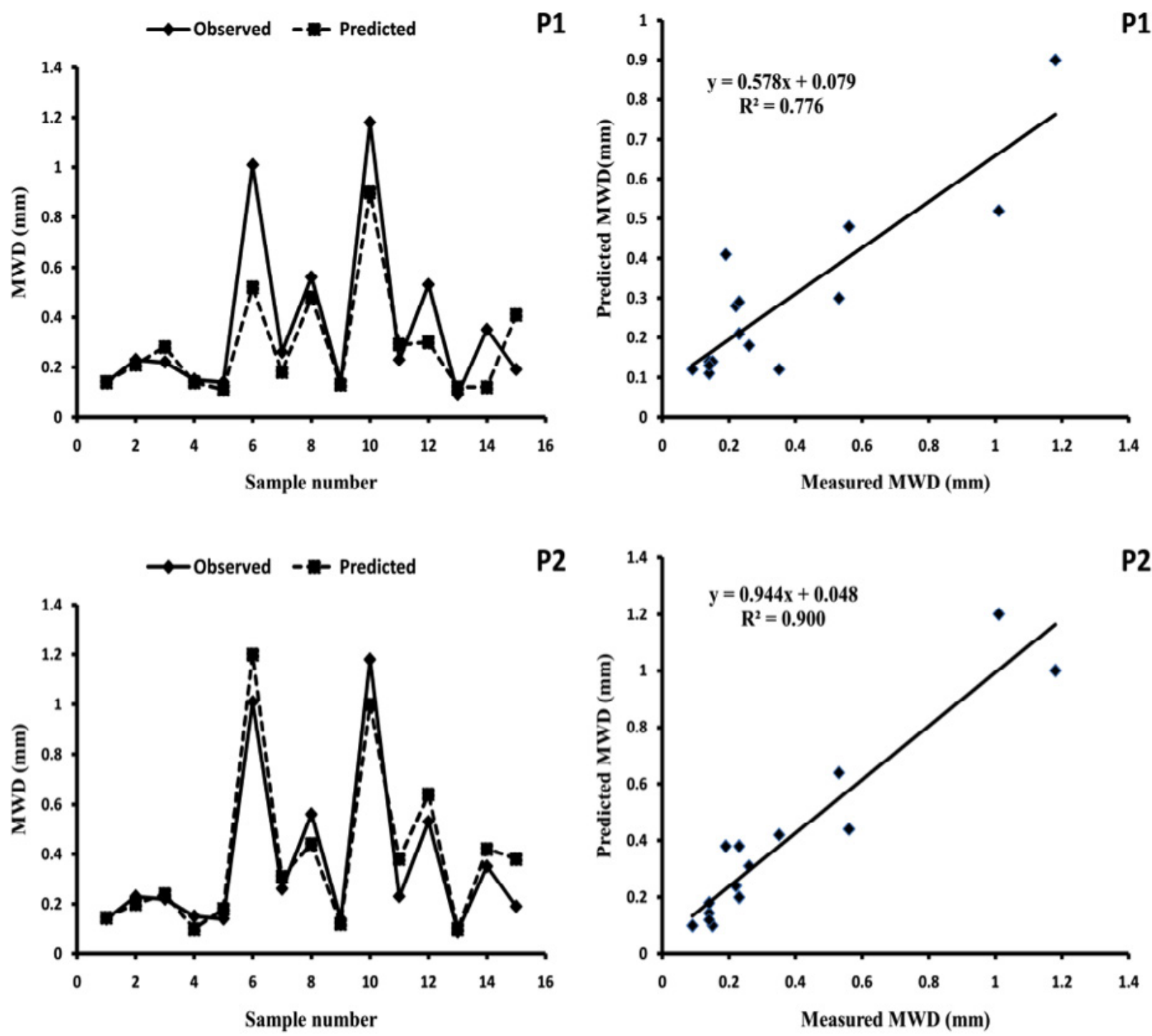

P2

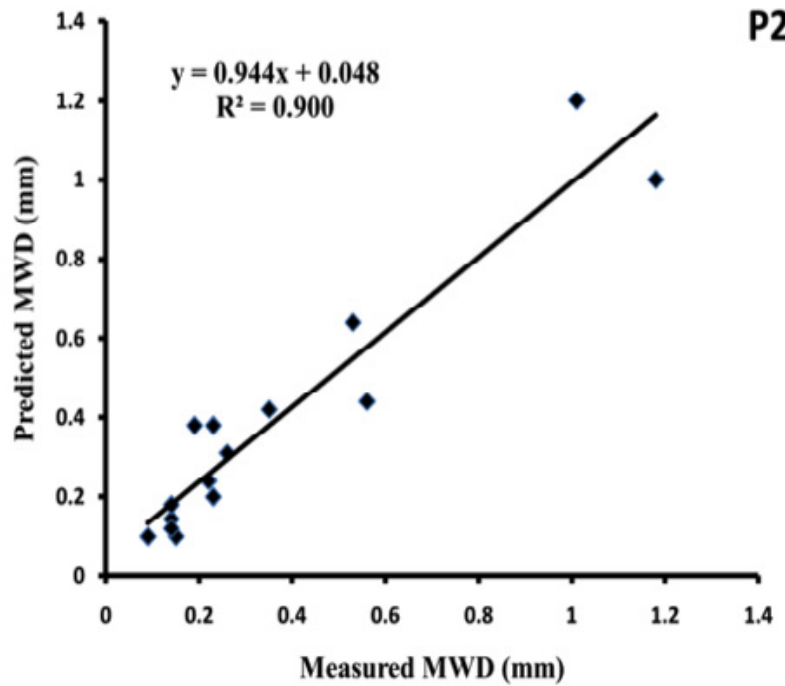

Figure 3. Relationship between the predicted and measured values of MWD by MLR models for validation dataset (P1 and P2 means that the model developed without and with using Dn as a predictor in modeling, respectively).

models for the prediction of swell potential of clayey soils. They reported that RBF exhibited a higher performance than MLP, ANFIS and MR for predicting swell potential. Kalkan et al. (2009) used the ANNs method to develop a model for the prediction of unconfined compressive strength (UCS). They used clay content, fine silt content, coarse silt content, fine sand content, middle sand content, coarse sand content, and gravel content of the total soil mass as independent variables. For the calibration of model, they subjected 84 soil samples to the unconfined compressive tests under laboratory conditions. They used 64 data for the calibration of the model and 20 data for test. Finally, they observed that their ANN model predicted the testing data effectively $\left(R^{2}=0.86\right)$.

Overall, the comparison of the models showed that ANN was more feasible in predicting and gave more perfect predictions of MWD than MLR. ANN is able to recognize the connection of information with less data for distributed and parallel computing natures, while MLR requires 

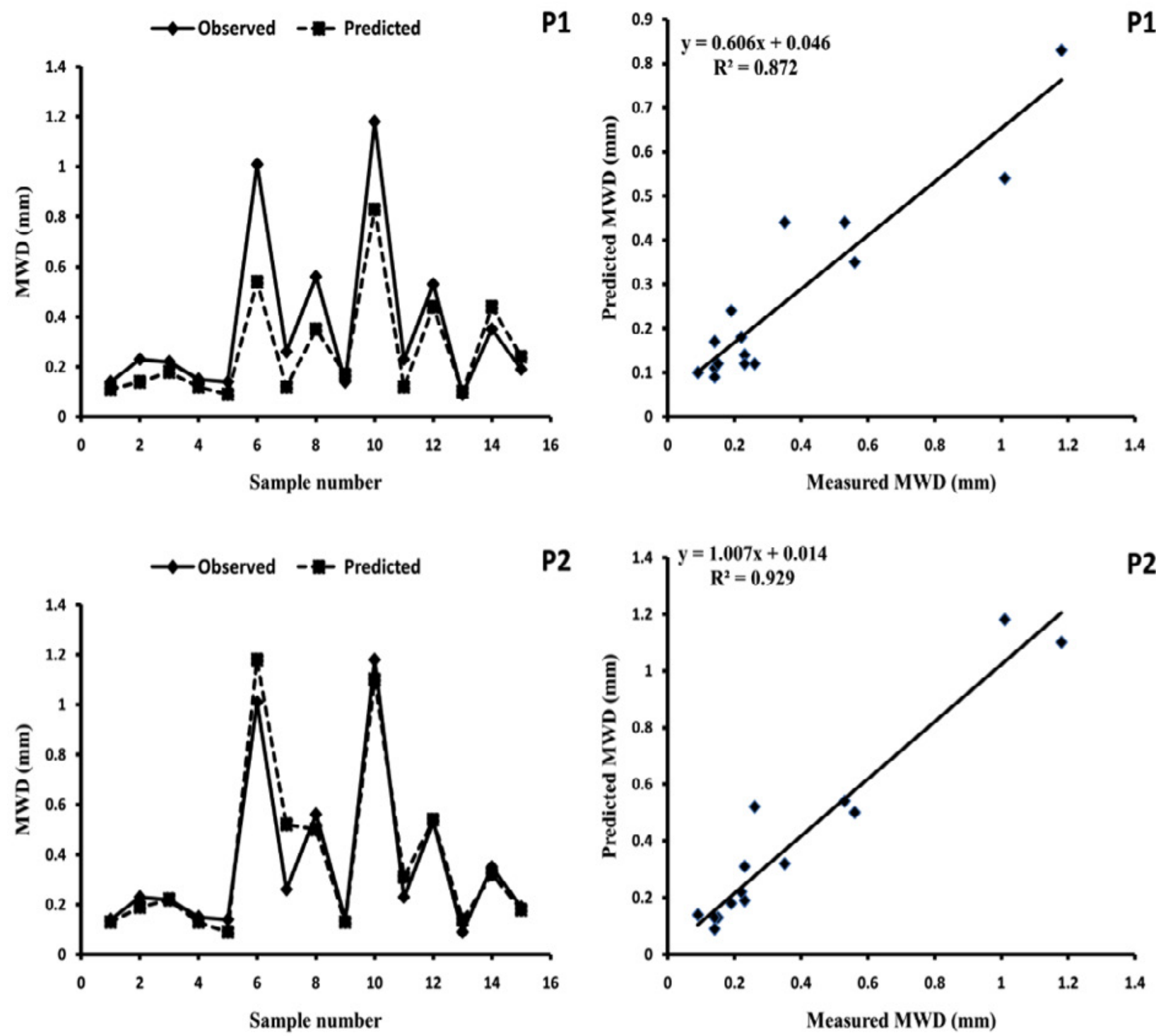

Figure 4. Relationship between the predicted and measured values of MWD by ANN model for validation dataset (P1 and P2 means that the model developed without and with using Dn as a predictor in modeling, respectively).

a large amount of data for the predication of unknown data, which is the main reason for the priority of ANN over MLR. Several studies have shown that ANN is appropriate for nonlinear relationships (Yilmaz and Kaynar 2011; Besalatpour et al. 2013). Since the fractal geometry was introduced as a predictor of soil texture-related properties (Liu et al. 2009), and the heterogeneity of soil structure could be described by fractal mathematics (Prosperini and Perugini 2008), it was expected that addition of Dn to soil properties could increase
$\mathrm{R}^{2}$ value in prediction of SAS indexes. According to the results, the use of a combination of fractal geometry and soil properties as the input dataset (P2) give a lower RMSE, MAPE, and MAD and higher $\mathrm{R}^{2}$ values rather than using soil properties alone (P1). Kalkan et al. (2009) concluded that the intelligent artificial systems (ANNs and ANFIS) performed better than empirical methods for the prediction of the unconfined compressive strength of compacted soils. Finally, the results indicate that ANN approach may always be a better choice for predicting MWD. 


\section{Conclusions}

SAS index is known as a main indicator of erodibility and resistivity to mechanical stresses of soil. There are numerous ways of showing SAS; the determination of the MWD of soil aggregates is the most common method. In addition, Dn has been known as another method to describe SAS. Thus, we tested and compared the performance ANN and MLR in predicting MWD (as SAS indexes) with different input datasets. The best answer was obtained using ANN (with the combination of soil properties and Dn as dataset) with the RMSE of 0.09 and determination coefficient of 0.9643 . Prediction of MWD using P1 dataset (soil properties alone) resulted in the lowest $R^{2}$-value. Addition of $D n$ to soil properties (P2) as input data improved the prediction of both methods. As the result, the ANN model generally shows greater potential in predicting MWD from routine properties of soil, whereas MLR indicated better correlation with the second dataset.

\section{Acknowledgements}

The authors would like to thank Islamic Azad University, Science and Research Branch and University of Tabriz for their aid and facilities.

\section{REFERENCES}

- Ahmadi A, Neyshabouri MR, Rouhipour H, Asadi H. 2011. Fractal dimension of soil aggregates as an index of soil erodibility. J Hydrol. 400(3):305-311.

-Alijanpour Shalmani A, Shabanpour M, Asadi H, Bagheri F. 2011. Estimation of soil aggregate stability in forest's soils of Guilan province by artificial neural networks and regression pedotransfer functions. Water Soil Sci. 21(3):153-162.

- Besalatpour AA, Ayoubi S, Hajabbasi MA, Mosaddeghi MR, Schulin R. 2013. Estimating wet soil aggregate stability from easily available properties in a highly mountainous watershed. Catena 111:72-79.

- Besalatpour A, Hajabbasi MA, Ayoubi S, Afyuni M, Jalalian A, Schulin R. 2012. Soil shear strength prediction using intelligent systems: artificial neural networks and an adaptive neuro-fuzzy inference system. Soil Sci Plant Nutr. 58(2):149-160.

- Bocco M, Willington E, Arias M. 2010. Comparison of regression and neural networks models to estimate solar radiation. Chil J Agric Res. 70(3):428-435.

- Bower CA, Reitemeier RF, Fireman M. 1952. Exchangeable cation analysis of saline and alkali soils. Soil Sci. 73: 251-261.

- Cañasveras JC, Barrón V, Del Campillo MC, Torrent J, Gómez JA. 2010. Estimation of aggregate stability indices in Mediterranean soils by diffuse reflectance spectroscopy. Geoderma 158(1):78-84.

- de Boer DH, Stone M, Lévesque LMJ. 2000. Fractal dimensions of individual particles and particle populations of suspended solids in streams. Hydrol Processes 14:653-667.

- Dimoyiannis DG, Tsadilas CD, Valmis S. 1998. Factors affecting aggregate instability of Greek agricultural soils. Commun Soil Sci Plant Anal. 29(9-10):1239-1251.

- Gago J, Martínez-Núñez L, Landín M, Gallego PP. 2010. Artificial neural networks as an alternative to the traditional statistical methodology in plant research. J Plant Physiol. 167(1):23-27.

- Gee GW, Or D. 2002. Particle-size analysis. In: Warren $A D$, editor. Methods of Soil Analysis. Part 4. Physical Methods. Madison, WI: Soil Sci. Soc. Am., Inc. p. 255295.

- Huang Y, Lan Y, Thomson SJ, Fang A, Hoffmann WC, Lacey RE. 2010. Development of soft computing and applications in agricultural and biological engineering. Comput Electron Agr. 71(2):107-127.

- Idowu OJ. 2003. Relationships between aggregate stability and selected soil properties in humid tropical environment. Commun Soil Sci Plant Anal. 34(5-6):695708. 
- Igwe C, Mbagwu J. 1995. Physical properties of soils of Southeastern Nigeria and the role of some aggregating agents in their stability. Soil Sci. 160(6):431-441.

- Kalkan E, Akbulut S, Tortum A, Celik S. 2009. Prediction of the unconfined compressive strength of compacted granular soils by using inference systems. Environ Geol. 58(7):1429-1440.

- Kisi Ö. 2004. Multi-layer perceptrons with LevenbergMarquardt training algorithm for suspended sediment concentration prediction and estimation. Hydrol Sci J. 49(6):1025-1040.

- Kisi O, Haktanir T, Ardiclioglu M, Ozturk O, Yalcin E, Uludag S. 2009. Adaptive neuro-fuzzy computing technique for suspended sediment estimation. Adv Eng Software 40(6):438-444

- Lentzsch P, Wieland R, Wirth S. 2005. Application of multiple regression and neural network approaches for landscape-scale assessment of soil microbial biomass. Soil Biol Biochem. 37(9):1577-1580

- Liu X, Zhang G, Heathman GC, Wang Y, Huang CH 2009. Fractal features of soil particle-size distribution as affected by plant communities in the forested region of Mountain Yimeng, China. Geoderma 154(1):123-130.

- Nimmo JR, Perkins KS. 2002. Aggregate stability and size distribution. In: Warren AD, editor. Methods of Soil Analysis. Part 4. Physical Methods. Madison, WI: Soil Sci. Soc. Am., Inc. p. 317-328.

- Parent LE, Parent SE, Kätterer T, Egozcue JJ. 2011. Fractal and compositional analysis of soil aggregation. In: Proceedings of the CoDaWork 2011, 4th International Workshop on Compositional Data Analysis; 2011 May 9-13; Girona, Spain; p. 1-14

- Prosperini N, Perugini D. 2008. Particle size distributions of some soils from the Umbria Region (Italy): fractal analysis and numerical modeling. Geoderma 145(3):185195.

- Rasiah V, Kay BD. 1994. Characterizing changes in aggregate stability subsequent to introduction of forages. Soil Sci Soc Am J. 58(3):935-942.

- Rieu M, Sposito G. 1991. Fractal fragmentation, soil porosity, and soil water properties: II. Applications. Soil Sci Soc Am J. 55(5):1239-1244.

- Saffari M, Yasrebi J, Sarikhani F, Gazni R, Moazallahi M, Fathi H, Emadi M. 2009. Evaluation of Artificial Neural Network Models for Prediction of Spatial Variability of Some Soil Chemical Properties. Res J Biol Sci. 4(7):815820.

- Silva RB, lori P, Armesto C, Bendini HN. 2010. Assessing rainfall erosivity with artificial neural networks for the Ribeira Valley. Brazil. Intl J Agron.:1-7.

- Sobhani J, Najimi M, Pourkhorshidi AR, Parhizkar T. 2010. Prediction of the compressive strength of noslump concrete: A comparative study of regression, neural network and ANFIS models. Construc Build Mater. 24:709-718.
- Sparks DL, Page AL, Helmke PA, Loeppert RH, Soltanpour PN, Tabatabai MA, Sumner ME. 1996. Methods of soil analysis. Part 3. Chemical methods. Madison, WI: Soil Science Society of America Inc.

- Tracey JA, Zhu J, Crooks KR. 2011. Modeling and inference of animal movement using artificial neural networks. Environ Ecol Stat. 18(3):393-410.

- Trasar-Cepeda, C, Leiros C, Gil-Sotres F, Seoane S. 1998. Towards a biochemical quality index for soils: an expression relating several biological and biochemical properties. Biol Fertil Soils 26(2):100-106.

-Walkey JA, Black JA. 1934. Estimation of organic carbon by the chromic acid titration method. Soil Sci. 37:29-31.

- Yilmaz I, Kaynar O. 2011. Multiple regression, ANN (RBF, MLP) and ANFIS models for prediction of swell potential of clayey soils. Expert Sys Appl. 38(5):59585966.

- Zhao SW, Jing SU, Yang YH, Liu NN, Wu JS, Shangguan ZP. 2006. A fractal method of estimating soil structure changes under different vegetations on Ziwuling Mountains of the Loess Plateau, China. Agr Sci China 5(7):530-538.

- Zornoza R, Mataix-Solera J, Guerrero C, Arcenegui V, García-Orenes F, Mataix-Beneyto J, Morugán A. 2007. Evaluation of soil quality using multiple lineal regression based on physical, chemical and biochemical properties. Sci Total Environ. 378(1):233-237. 